Electronic Supplementary Information

\title{
High-Throughput Platform for Real-Time Monitoring of ATP-generating Enzymes in Living Cells Based on a Lanthanide Probe
}

\author{
Moustafa T. Gabr, ${ }^{a *}$ Anand Balupuri, ${ }^{\mathrm{b}}$ and Nam Sook Kang ${ }^{\mathrm{b}}$ \\ ${ }^{a}$ Department of Radiology, Stanford University School of Medicine, Stanford, CA, 94305. Email: \\ gabr2003@gmail.com \\ ${ }^{b}$ Graduate School of New Drug Discovery and Development, Chungnam National University, Daejeon 305-764, \\ Republic of Korea.
}

\section{Contents}

Experimental

S3

Dynamic light scattering (DLS) analysis of 1-Tb $(100 \mu \mathrm{M})$ in 99:1 $\mathrm{H}_{2} \mathrm{O}: \mathrm{MeOH}$ in the absence

(A) and presence (B) of ATP $(20 \mu \mathrm{M})$

The correlation between dextran concentration (\%w/w) added to low glucose DMEM cell

culture media and the viscosity of solution

The change of luminescence lifetime of 1-Tb (1 mM) in 99:1 $\mathrm{H}_{2} \mathrm{O}: \mathrm{MeOH}$ at different

viscosities adjusted by dextran \%.

The change of luminescence lifetime of 1-Tb (1 mM) in 99:1 $\mathrm{H}_{2} \mathrm{O}: \mathrm{MeOH}$ at different

viscosities adjusted by dextran $\%$ in the presence of ATP $(20 \mu \mathrm{M})$.

Luminescence lifetime values of 1-Tb as a function of added ATP to PC-3 cells

Luminescence lifetime values of $\mathbf{1 - T b}$ as a function of added ATP to MCF-7 cells

Luminescence lifetime values of 1-Tb as a function of added ATP to HEK-293 cells

Luminescence lifetime values of 1-Tb as a function of added ATP to HEY cells

S10

Luminescence lifetime values of 1-Tb as a function of added ATP to JB6P+ cells

S11

$\%$ Cell viability as demonstrated by MTT assay upon incubation of 1-Tb $(100 \mu \mathrm{M})$ with (A)

HEY, (B) HEK-293, (C) PC-3, and (D) MCF-7 cells

PKM2 activity as determined by LDH-coupled assay at different viscosities of the solution

S12

Flow cytometry analysis of PKM2 in (A) HEY cells with silenced PKM2 expression and (B) HEY

cells overexpressing PKM2

Detection of PKM2 in cell lysates of HEY cells with silenced PKM2 expression and HEY cells overexpressing PKM2 using PKM2 ELISA 
Changes in luminescence lifetime values of 1-Tb as a function of added PEP concentration to HEY cells

Changes in luminescence lifetime values of 1-Tb $(0.1 \mathrm{mM})$ as a function of time in the

presence of PEP $(1 \mu \mathrm{M})$ in HEY cells overexpressing PKM2

Dose-response curve of compound S1 in LDH-coupled assay for PKM2 activity

Dose-response curve of compound S1 in PKM2 ELISA assay

Chemical structures of compounds S1-S3

S15

Superimposition of docked poses of compounds S1-S3

S16

Docked binding mode and interactions of compound $\mathbf{S 1}$ inside active site of hPKM2

S16

Docked binding mode and interactions of compound $\mathbf{S 2}$ inside active site of hPKM2

Docked binding mode and interactions of compound $\mathbf{S 3}$ inside active site of hPKM2

S17

Changes in luminescence lifetime values of 1-Tb as a function of added PEP concentration

to HEY cells overexpressing PKM1

Changes in luminescence lifetime values of 1-Tb as a function of added phosphocreatine

concentration to human skeletal muscle fibroblasts expressing muscle creatine kinase

Changes in luminescence lifetime values of 1-Tb as a function of added phosphocreatine

S19

concentration to cardiomyocytes expressing mitochondrial creatine kinase

Changes in luminescence lifetime values of 1-Tb as a function of added ADP concentration

to PC-3M expressing ATP synthase

Effect of viscosity on $V_{\max }$ of PKM2 in HeLa cells

S20

Optimized viscosities for screening ATP-generating enzymes

S20

References

S2O 


\section{Experimental}

\section{Synthesis of 1-Tb and its nanostructure formation}

The synthesis, nanostructure formation, and characterization of 1-Tb was done as previously reported. ${ }^{1}$ Stock solution of 1-Tb (1 mM) was prepared in $50.0 \mathrm{mM}$ HEPES buffer $(10 \mathrm{mM} \mathrm{NaCl}, 1 \mathrm{mM} \mathrm{MgCl}$, $\mathrm{pH}$ 7.4) were prepared.

\section{Cellular determination of lifetime in the presence of ATP}

Cell lines were obtained from American Type Culture Collection (ATCC). Cells were cultured in low glucose DMEM medium with 10\% Fetal Bovine Serum (FBS), 100 units $/ \mathrm{mL}$ penicillin and $100 \mu \mathrm{g} / \mathrm{mL}$ streptomycin. All cells were grown at $37{ }^{\circ} \mathrm{C}$ in a humidified atmosphere containing $5 \% \mathrm{CO}_{2}$. Cells $\left(4 \times 10^{5}\right.$ cell/well) were plated in 12-well dishes. Lifetime measurements were done using an LF502 Nanoscan FLTTRF (IOM, Berlin, Germany), equipped with a laser as excitation source $\left(\lambda_{\text {ex }}=337 \mathrm{~nm}\right)$.

\section{Changing cell culture media viscosity using dextran}

The viscosity of the cell culture medium was altered with dextran (MW 135,000) (Sigma Aldrich). Dextran powder was weighed and dissolved in cell culture medium. The solutions were allowed to degass and solubilize before filtering through a polyethersulfone membrane. The viscosity was verified by rheological testing with a double gap rheometer (Anton Paar $\mathrm{GmbH}$, Austria) at a constant temperature of $37^{\circ} \mathrm{C}$. Measurements were taken over a range of shear rates to verify the Newtonian behavior of the solutions. Density was measured using a pycnometer (Fisher Scientific, Part \# 03247Q).

\section{PKM2 expression vector construct}

PKM2 expression vector construct and establishment of HEY cells expressing PKM2 were done as previously reported. ${ }^{2}$ Briefly, human PKM2 CDNA was cloned into the pLVX-Neo-IRES-ZsGreen1 vector, Xhol and Notl restriction sites were inserted into the PCR products using the following primers: $5^{\prime}$ CCGCTCGAGATGTCGAAGCCCCATAGTGAAG-3' (forward) and ${ }^{\prime}$ 'ATAAGAATGCGGCCGCTCACGGCACAGGAACAACACGC-3' (reverse). The plasmid was cotransfected into 293T cells with the lentivirus packaging plasmids pMD2.G and psPAX2 to produce lentivirus particles. The PKM2 lentivirus particles were then used to transduce HEY ovarian cells. The overexpression of PKM2 was verified by flow cytometry analysis.

\section{Silencing PKM2 expression in HEY cells with PKM2 siRNA}

HEY cells with silenced expression of PKM2 was accomplished as previously reported. ${ }^{2}$ Briefly, PKM2 siRNA (targeting on the sites of 1280-1298 bp of PKM2) (sense: CCAUAAUCGUCCUCACCAATT, antisense: UUGGUGAGGACGAUUAUGGTT) was used to transfect HEY cells. The silenced expression of PKM2 was verified by flow cytometry analysis.

\section{Flow cytometry analysis:}

For the analysis of the expression of target enzymes in the used cells, flow cytometry analysis was performed. The cells were seeded on 6-well plates and cultured till sub-confluency. The cells were detached from the plates with Trypsin-ESTA, placed on ice, washed 2 times with Flow Cytometry Staining Buffer (eBioscience, Waltham, MA, USA) and stained with corresponding labelled antibody and isotype control. The cells were analyzed with the BD Biosciences FACSAria III. 


\section{Anchorage-Independent Growth Assay in Soft Agar}

Soft agar-based cell transformation assay was carried out in 6-well plates as previously described. ${ }^{3}$ The bottom agar was made using 1.25\% agar, 2× EMEM medium, 10\% FBS, PBS, glutamine, and penicillin, and incubated in a $50{ }^{\circ} \mathrm{C}$ water bath. The mixture $(0.5 \%$ agar) was then divided and various treatment reagents were added. In each well, $2.5 \mathrm{ml}$ of the $0.5 \%$ agar mix was added and allowed to harden for $30 \mathrm{~min}$. The top agar mix contained two fractions of the above $0.5 \%$ agar mixtures and one fraction of $1 \times 10^{4} \mathrm{JB} 6$ cells. The treatment reagents were added and $0.75 \mathrm{ml}$ of the top agar mix was transferred on top of the bottom agar. The agar was allowed to solidify and incubated in a $37^{\circ} \mathrm{C}$ incubator under $5 \% \mathrm{CO}_{2}$ for 14 days followed by staining with $0.25 \mathrm{mg} / \mathrm{ml}$ Neutral Red for $24 \mathrm{~h}$.

\section{Lactate dehydrogenase (LDH)-coupled assay for PKM activity}

PKM activity was analyzed using the lactate dehydrogenase (LDH)-coupled assay as described previously. ${ }^{4}$ The standard assay mixture contains the following reagents in a final volume of $400 \mu \mathrm{l}: 10$ $\mathrm{mmol} / \mathrm{L}$ Tris-acetate, $\mathrm{pH} 7.5 ; 10 \mathrm{mmol} / \mathrm{L} \mathrm{MgCl}$; $50 \mathrm{mmol} / \mathrm{L} \mathrm{KCl} ; 2 \mathrm{mmol} / \mathrm{L} \mathrm{ADP} ; 10 \mathrm{mmol} / \mathrm{L}$ phosphoenolpyruvate; 4.4 units of LDH; and $0.12 \mathrm{mmol} / \mathrm{L} \mathrm{NADH}$.

\section{PKM2 ELISA assay}

The assay was performed using PKM2 ELISA kit (MyBioSource, Catalog No. MBS2505089) according to the manufacturer's protocol.

\section{Dynamic Light Scattering (DLS)}

Particle size distribution analysis was measured by DLS experiments using a Malvern Zetasizer Nano ZS instrument.

\section{Cell viability assay}

Cells were maintained in culture dishes at $37{ }^{\circ} \mathrm{C}$ in a saturated humidity atmosphere containing $95 \%$ air and $5 \% \mathrm{CO}_{2}$. Cells were plated (5000 cells/well) in 96-well plates (Corning). 1-Tb (100 $\mu \mathrm{M}$ ) was added to the assay plates and incubated for $24 \mathrm{hrs}$. Cell viability was determined by measuring mitochondrial activity using the MTT (3-(4,5-dimethylthiazole-2-yl)-2,5-diphenyltetrazolium bromide) assay. After the incubation time, the medium was removed and cells were incubated with $100 \mu \mathrm{lMTT}(0.5 \mathrm{mg} / \mathrm{ml})$ for $1 \mathrm{~h}$. After that, the solution was removed, the formazan formed solubilized in $100 \mu \mathrm{l}$ of $0.1 \mathrm{~N} \mathrm{HCl}$ in $90 \%(\mathrm{v} / \mathrm{v})$ 2-propanol and the absorbance was measured at $570 \mathrm{~nm}$ using a microplate reader (BioRad 680, USA).

\section{Validation of the assay for high-throughput screening (HTS):}

The suitability of the assay for HTS was validated by calculating three screen parameters (signal-to-noise ratio $(\mathrm{S} / \mathrm{N})$, signal-to-background ratio (S/B) and $Z^{\prime}$ factor) using the following equations: ${ }^{5}$

$\mathrm{S} / \mathrm{N}=\frac{\text { mean signal of }+ \text { ve control }- \text { mean background }}{\text { standard deviation of background }}$

$\mathrm{S} / \mathrm{B}=\frac{\text { mean signal of }+ \text { ve control }}{\text { mean background }}$

$Z^{\prime}$ factor $=1-\frac{(S . D .+v e)+(S . D .-v e)}{(\text { mean }+v e)-(\text { mean }-v e)}$

Where, S.D. +ve : Standard deviation of the positive control

S.D. - ve: Standard deviation of the negative control 
Mean +ve : mean of the positive controls

Mean -ve : mean of the negative controls

$Z^{\prime}$ factor was calculated using 40 plates run in 384-well format.

\section{Screening ChemBridge DIVERSet library for PKM2 modulators}

The procedure for the screening was performed as shown below:

1. HEY cells (both with expressed and silenced PKM2 separately) were cultured in Corning ${ }^{\circledR} \mathrm{T}-75$ flasks (catalog \#430641) in low glucose DMEM medium with 10\% Fetal Bovine Serum (FBS), 100 units $/ \mathrm{mL}$ penicillin and $100 \mu \mathrm{g} / \mathrm{mL}$ streptomycin at $37^{\circ} \mathrm{C}$ in a humidified atmosphere containing $5 \% \mathrm{CO}_{2}$.

2. One day prior to the screening assay, the growth medium for HEY cells was exchanged with DMEM medium with modified viscosity $\left(7.5 \% \mathrm{w} / \mathrm{w}\right.$ dextran was added). HEY cells $\left(3 \times 10^{4}\right.$ cell/well) were plated overnight in 384-well plates (Greiner \#784075) at $37{ }^{\circ} \mathrm{C}$ in a humidified atmosphere containing $5 \% \mathrm{CO}_{2}$.

3. After plating the cells for $14 \mathrm{hrs}$, the growth medium was exchanged with $10 \mu \mathrm{l}$ final volume consisting of: $10 \mathrm{mmol} / \mathrm{L}$ Tris-acetate, $\mathrm{pH} 7.5 ; 10 \mathrm{mmol} / \mathrm{L} \mathrm{MgCl} ; 50 \mathrm{mmol} / \mathrm{L} \mathrm{KCl} ; 2 \mathrm{mmol} / \mathrm{L} \mathrm{ADP}$, $7.5 \% \mathrm{w} / \mathrm{w}$ dextran, $10 \mathrm{mmol} / \mathrm{L}$ phosphoenolpyruvate and $1 \mathrm{mM}$ of 1-Tb.

4. Immediately, stock solutions from the chemical library in DMSO $(50 \mathrm{~nL})$ were applied to 384-well plates at a final concentration of $10 \mu \mathrm{M}$ in a single dose screening.

5. Subsequently, after a brief 30 -s shake, the plates were incubated in $5 \% \mathrm{CO}_{2}$ at $37^{\circ} \mathrm{C}$ in a humidified incubator for $20 \mathrm{~min}$.

6. After the incubation period $(20 \mathrm{~min}$ ), lifetime measurements (delay time: 0 , gate time: $40 \mathrm{~ms}$, time resolution: $1.0 \mu \mathrm{s}$ ) were done using LF502 Nanoscan FLT-TRF (IOM, Berlin, Germany), equipped with a laser as excitation source $\left(\lambda_{\mathrm{ex}}=337 \mathrm{~nm}\right)$. The difference in the lifetime measurements between the 2 cell types (with overexpressed and silenced PKM2) corresponds to ATP production mediated by PKM2.

7. Hits were defined as compounds that induced a change in luminescence lifetime of 1-Tb between HEY overexpressing PKM2 and HEY cells with silenced PKM2 expression higher than a cutoff value defined by the mean plus twice the standard deviation and were submitted to a retest in an identical assay.

8. Autofluorescence of retest-positive hits was measured by dispensing each compound at $10 \mu \mathrm{M}$ (in 90\% DMSO) into the wells of a 384-well plate and measuring the fluorescence signal by using the same signal acquisition parameters as for the primary screening.

9. We next evaluated the dose-response profiles of all the inhibitor hits and determined their respective $I_{50}$ values. The dose-response curves were analyzed by nonlinear regression using GraphPad Prism 8.0.2 (GraphPad Software, Inc., La Jolla, CA, USA). Each data point from this assay represents the average of three independent measurements. Error bars represent standard deviation.

\section{Molecular Docking}

The X-ray crystal structure of human pyruvate kinase isozyme M2 (hPKM2) (PDB code: 1T5A, resolution: $2.80 \AA ̊$ ) was retrieved from the RCSB Protein Databank (PDB, https://www.rcsb.org/). Chain A of PDB 1T5A 
was used for docking. Three-dimensional (3D) structures of the compounds were built and energy minimized using Discovery Studio 2019 (BIOVIA, San Diego: Dassault Systèmes). Molecular docking was performed using AutoDock 4.2.6 software. Prior to docking, protein and ligand structures were processed using AutoDock Tools (ADT) 1.5.6. Co-crystallized ligands and water molecules were removed during the protein preparation. Hydrogen atoms were added to the protein. Kollman and Gasteiger charges were computed. During the preparation of ligands, Gasteiger charges and rotatable bonds were assigned. Protein was kept rigid whereas ligands were treated as flexible in the docking protocol. 3D affinity grid fields were generated using AutoGrid program. A grid of size $50 \times 50 \times 50 \AA 3$ with $0.375 \AA$ spacing was centered on the co-crystallized ligand (oxalate). A total of 100 docking runs, $25 \times 105$ energy evaluations and 27,000 iterations were carried out using Lamarckian genetic algorithm method (LGA). Default settings were used for all other parameters. Docked poses were selected on the basis of protein-ligand interactions and scoring functions. Discovery Studio 2019 was used for molecular visualizations (BIOVIA, San Diego: Dassault Systèmes). 

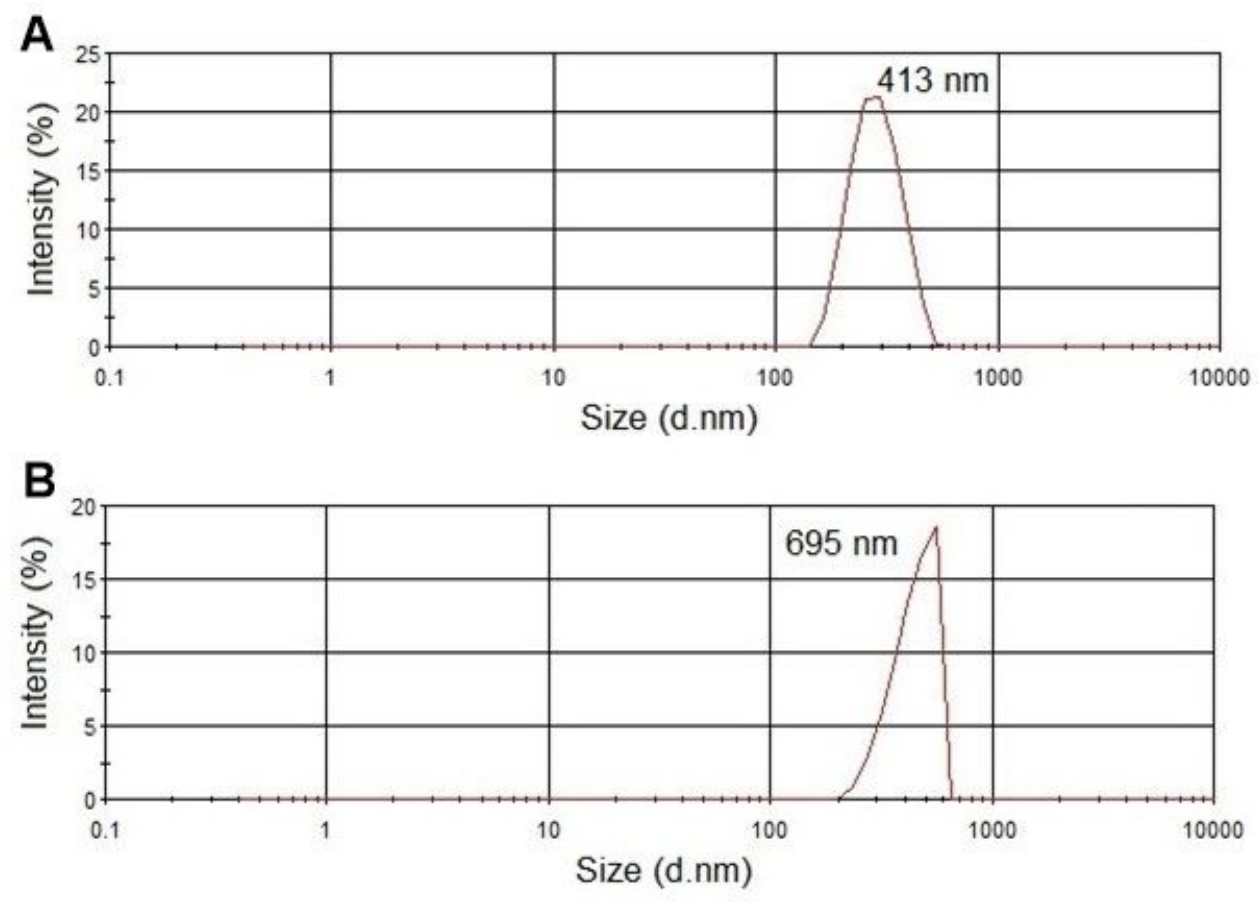

Fig. S1. Dynamic light scattering (DLS) analysis of 1-Tb $(100 \mu \mathrm{M})$ in 99:1 $\mathrm{H}_{2} \mathrm{O}: \mathrm{MeOH}$ in the absence $(\mathrm{A})$ and presence (B) of ATP $(20 \mu \mathrm{M})$.

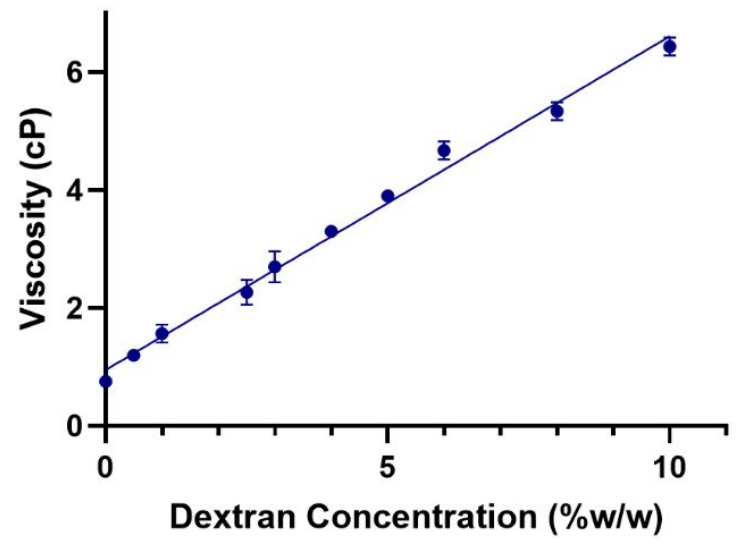

Fig. S2. The correlation between dextran concentration (\%w/w) added to low glucose DMEM cell culture media and the viscosity of solution. Error bars represent standard deviation $(n=3)$. 


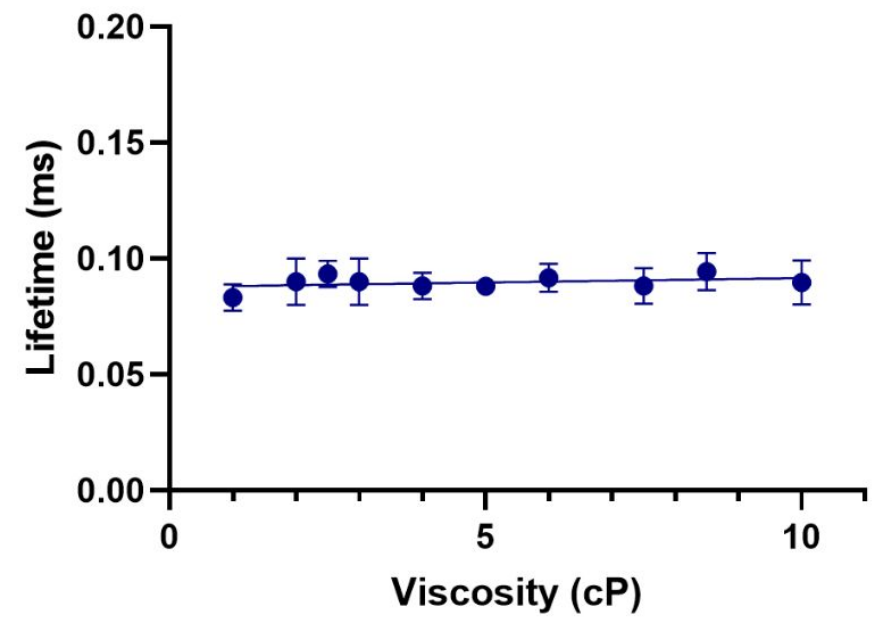

Fig. S3. The change of luminescence lifetime of 1-Tb $(1 \mathrm{mM})$ in 99:1 $\mathrm{H}_{2} \mathrm{O}: \mathrm{MeOH}$ at different viscosities adjusted by dextran \%. Error bars represent standard deviation $(n=3)$.

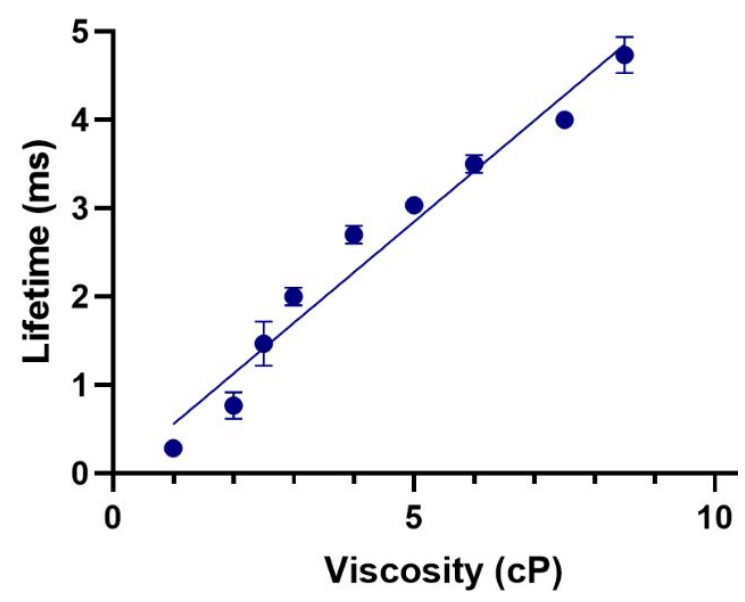

Fig. S4. The change of luminescence lifetime of 1-Tb $(1 \mathrm{mM})$ in 99:1 $\mathrm{H}_{2} \mathrm{O}: \mathrm{MeOH}$ at different viscosities adjusted by dextran $\%$ in the presence of ATP $(20 \mu \mathrm{M})$. Error bars represent standard deviation $(n=3)$. 


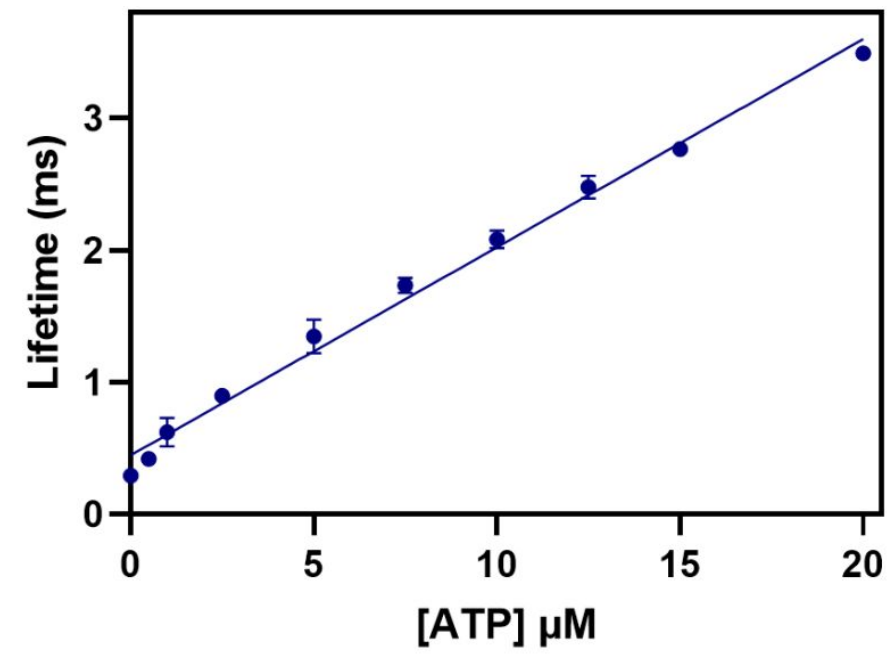

Fig. S5. Luminescence lifetime values of 1-Tb $(0.1 \mathrm{mM})$ as a function of added ATP concentration (0-20 $\mu \mathrm{M})$ to PC-3 cells $\left(\lambda_{\mathrm{ex}}=337 \mathrm{~nm}\right)$. Error bars represent standard deviation $(n=3)$.

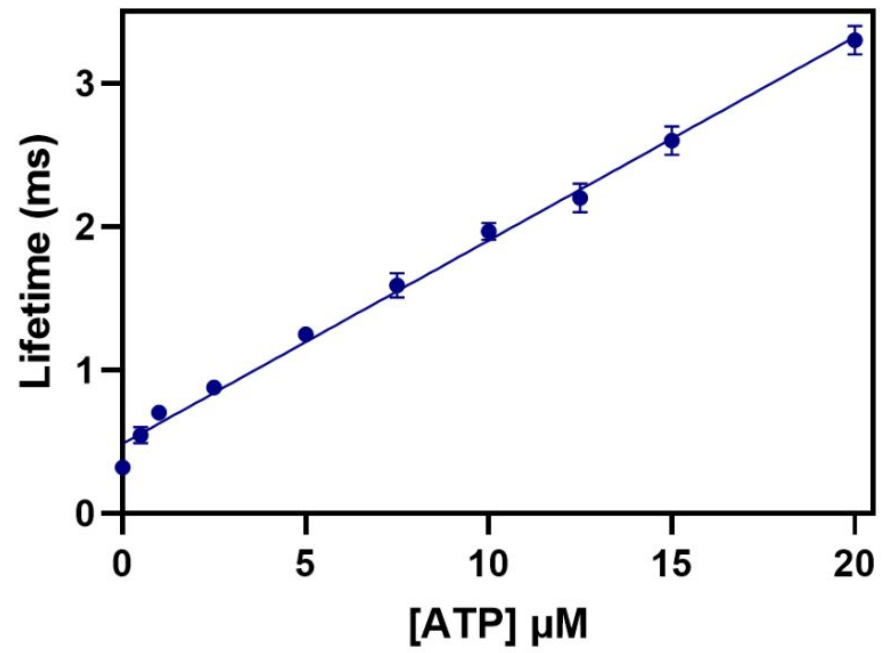

Fig. S6. Luminescence lifetime values of 1-Tb $(0.1 \mathrm{mM})$ as a function of added ATP concentration (0-20 $\mu \mathrm{M})$ to MCF-7 cells $\left(\lambda_{\mathrm{ex}}=337 \mathrm{~nm}\right)$. Error bars represent standard deviation $(n=3)$. 


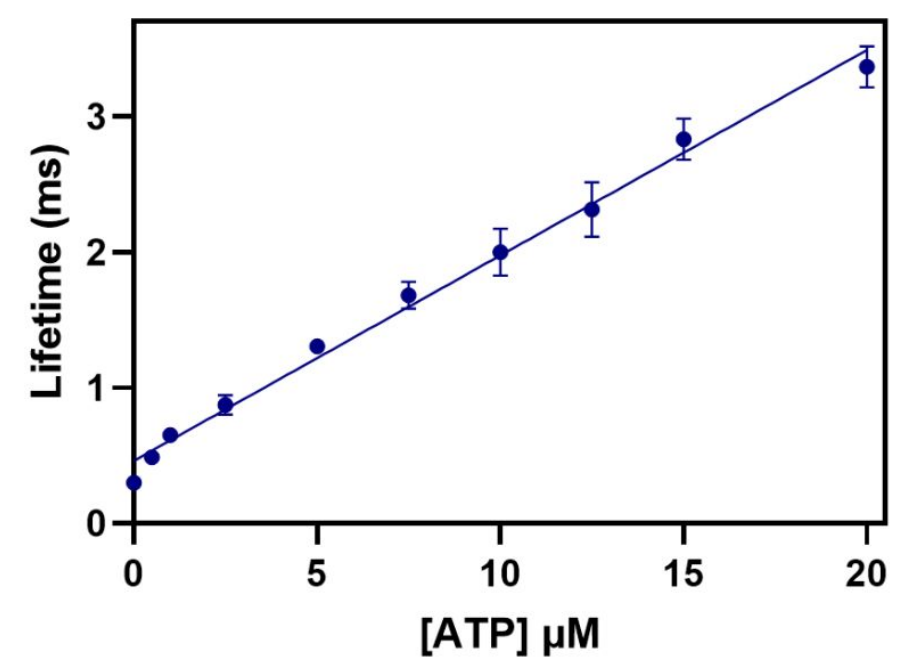

Fig. S7. Luminescence lifetime values of 1-Tb $(0.1 \mathrm{mM})$ as a function of added ATP concentration (0-20 $\mu \mathrm{M})$ to HEK-293 cells $\left(\lambda_{\mathrm{ex}}=337 \mathrm{~nm}\right)$. Error bars represent standard deviation $(n=3)$.

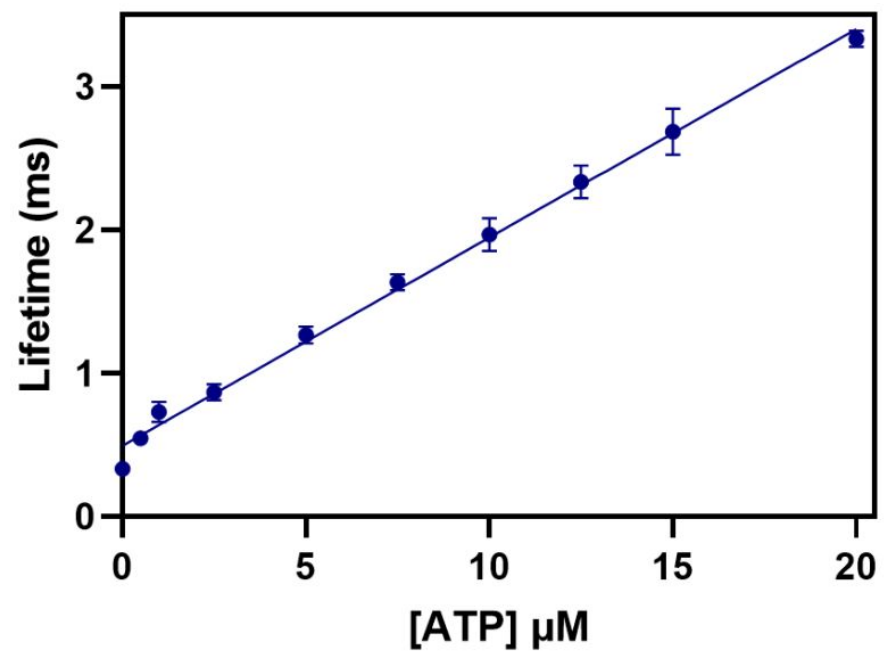

Fig. S8. Luminescence lifetime values of 1-Tb $(0.1 \mathrm{mM})$ as a function of added ATP concentration (0-20 $\mu \mathrm{M})$ to HEY cells $\left(\lambda_{\mathrm{ex}}=337 \mathrm{~nm}\right)$. Error bars represent standard deviation $(n=3)$. 


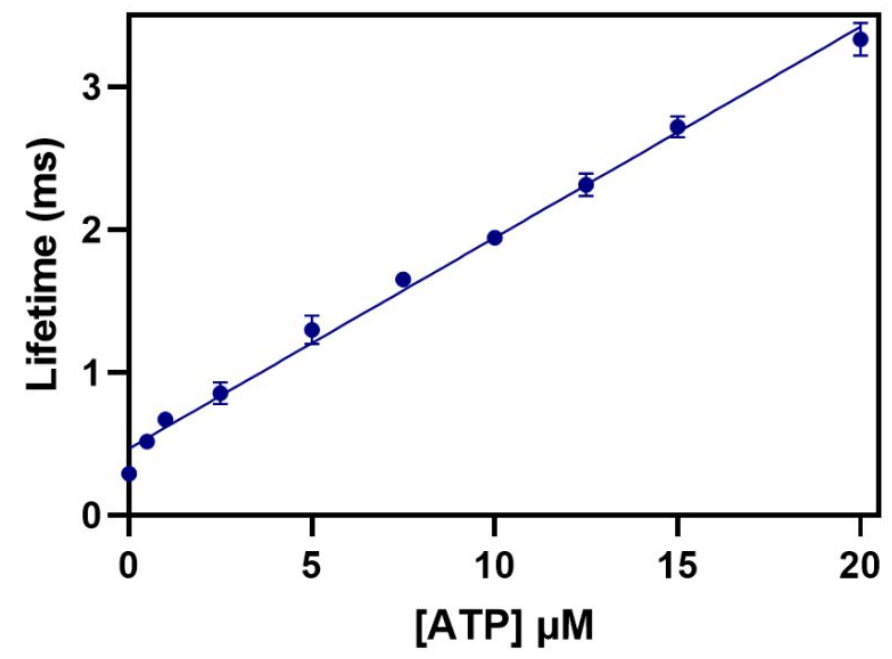

Fig. S9. Luminescence lifetime values of 1-Tb $(0.1 \mathrm{mM})$ as a function of added ATP concentration (0-20 $\mu \mathrm{M})$ to JB6P+ cells $\left(\lambda_{\mathrm{ex}}=337 \mathrm{~nm}\right)$. Error bars represent standard deviation $(\mathrm{n}=3)$.
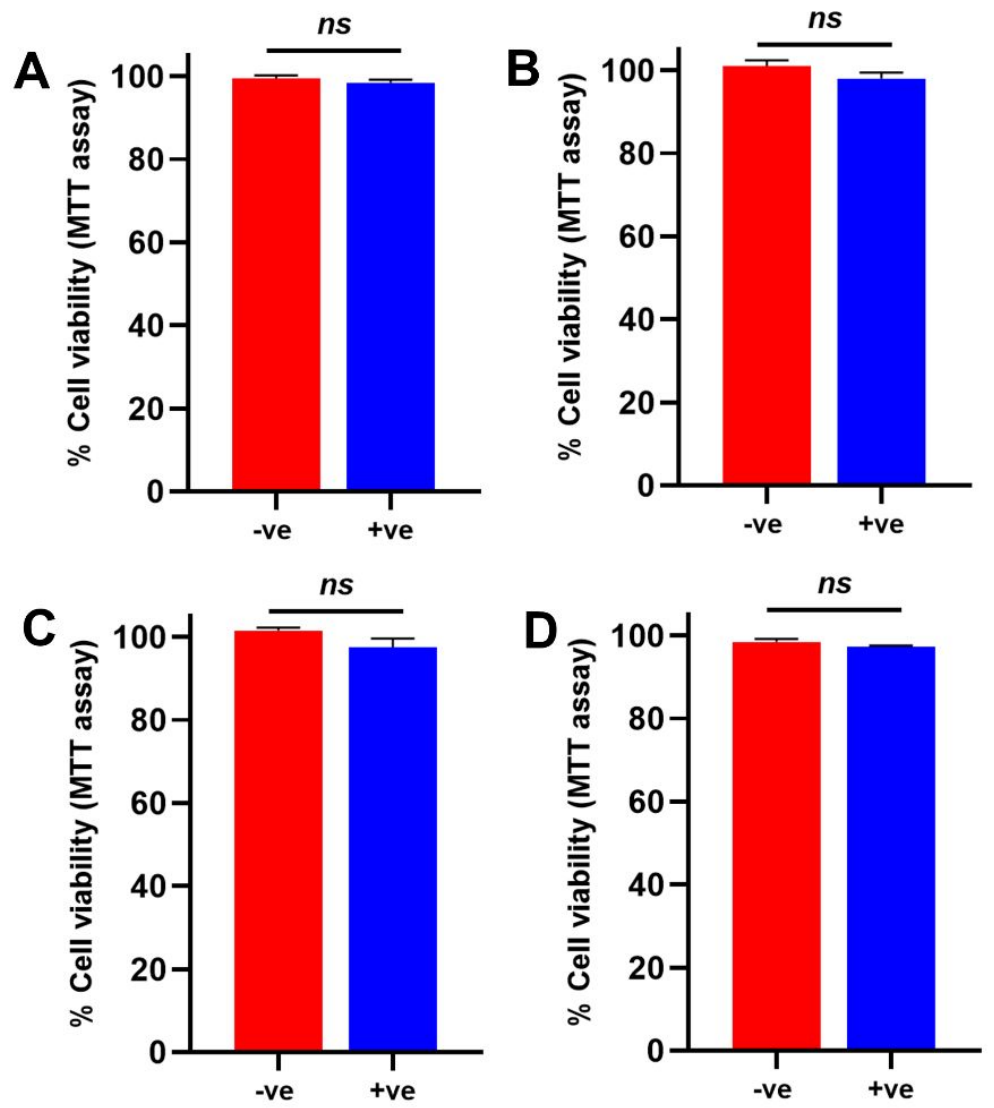

Fig. S10. \% Cell viability as demonstrated by MTT assay upon incubation of 1-Tb (100 $\mu \mathrm{M})$ with (A) HEY, (B) HEK-293, (C) PC-3, and (D) MCF-7 cells. Error bars represent standard deviation $(n=3)$. 


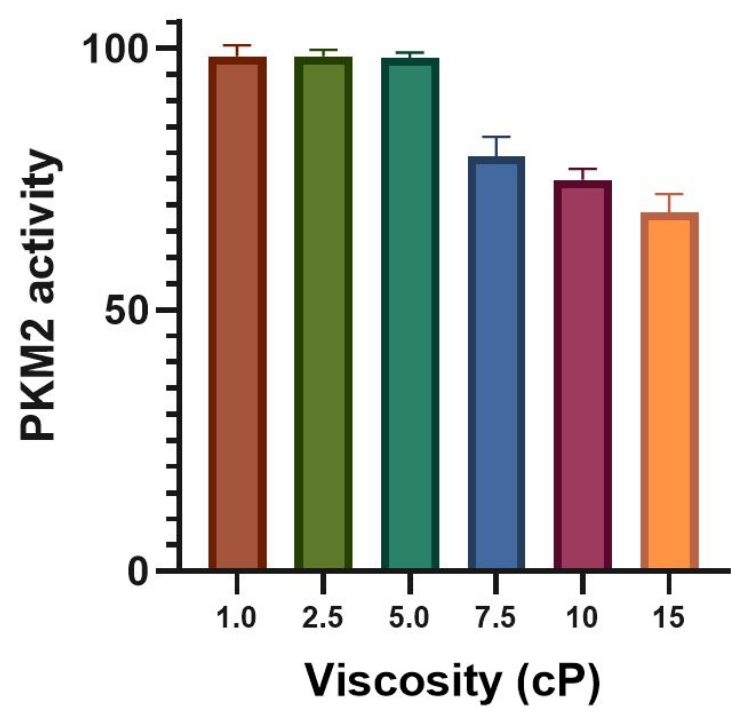

Fig. S11. PKM2 activity as determined by LDH-coupled assay at different viscosities of the solution. Error bars represent standard deviation $(n=3)$.
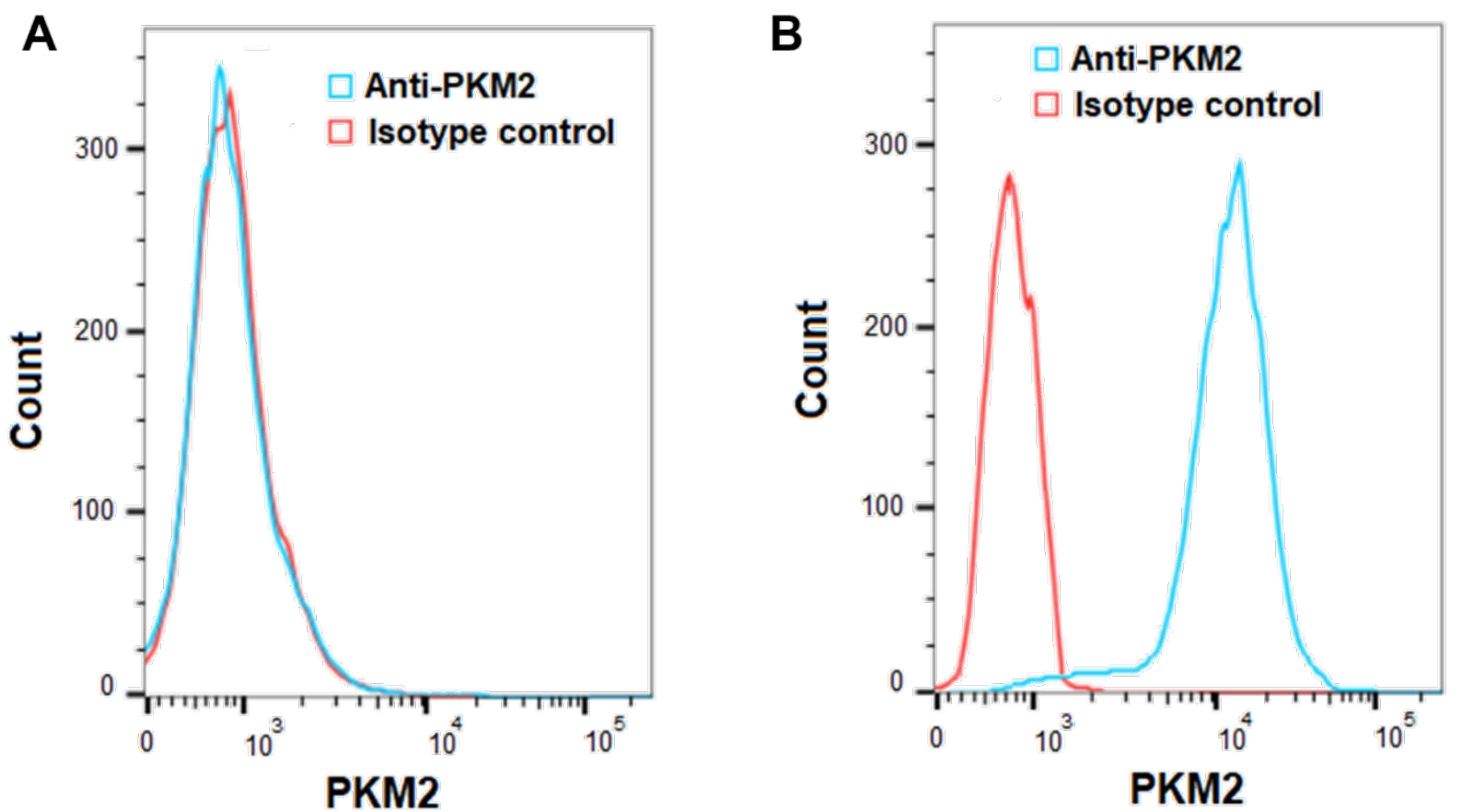

Fig. S12. Flow cytometry analysis of PKM2 in (A) HEY cells with silenced PKM2 expression and (B) HEY cells overexpressing PKM2. 


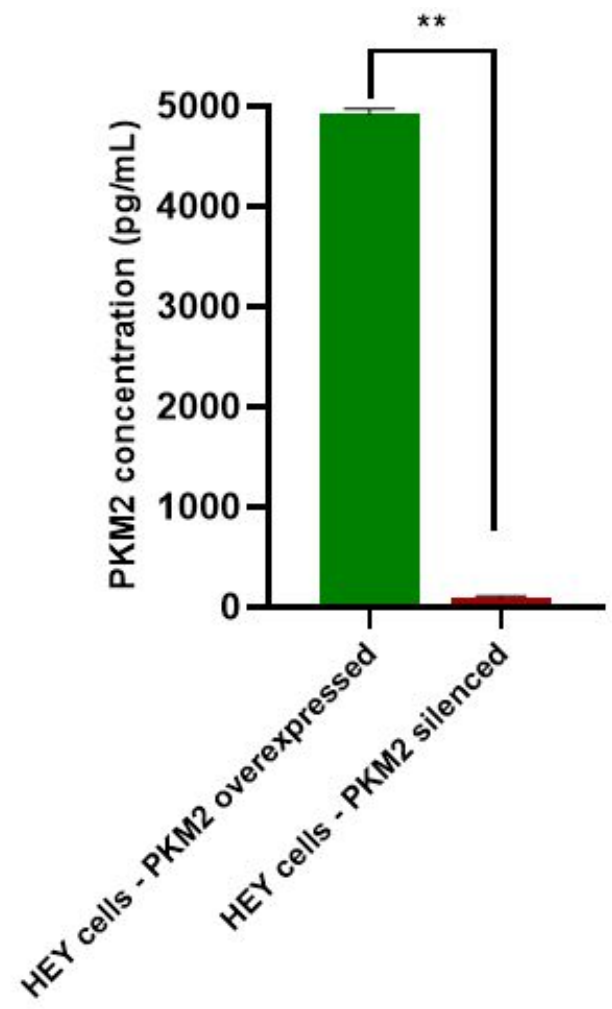

Fig. S13. Detection of PKM2 in cell lysates of HEY cells with silenced PKM2 expression and HEY cells overexpressing PKM2 using PKM2 ELISA. Error bars represent standard deviation $(n=3)$.

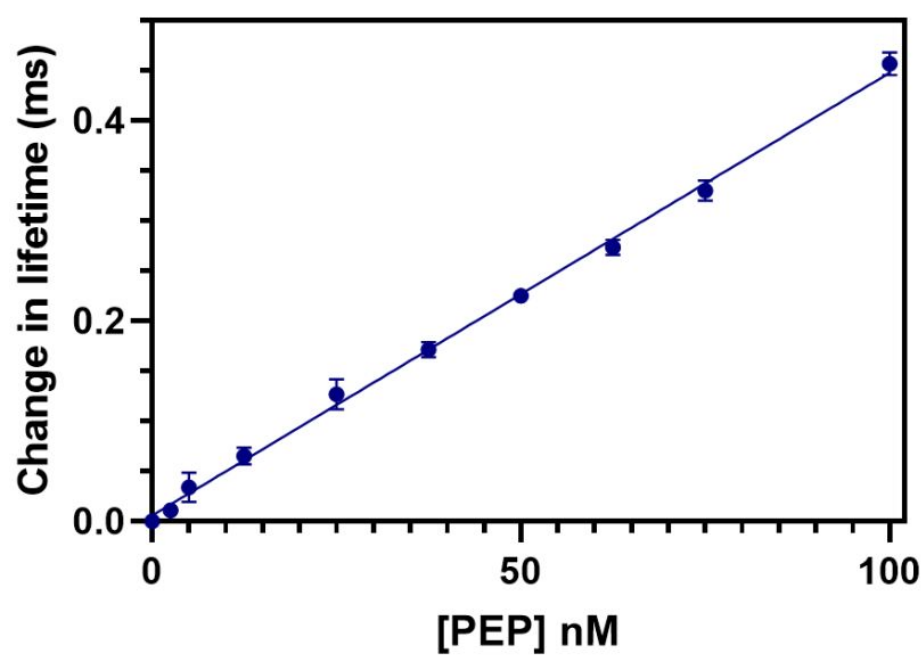

Fig. S14. Changes in luminescence lifetime values of 1-Tb $(0.1 \mathrm{mM})$ as a function of added PEP concentration (0-100 $\mathrm{nM}$ ) to HEY cells overexpressing PKM2 $\left(\lambda_{\mathrm{ex}}=337 \mathrm{~nm}\right)$. Error bars represent standard deviation $(n=3)$. 


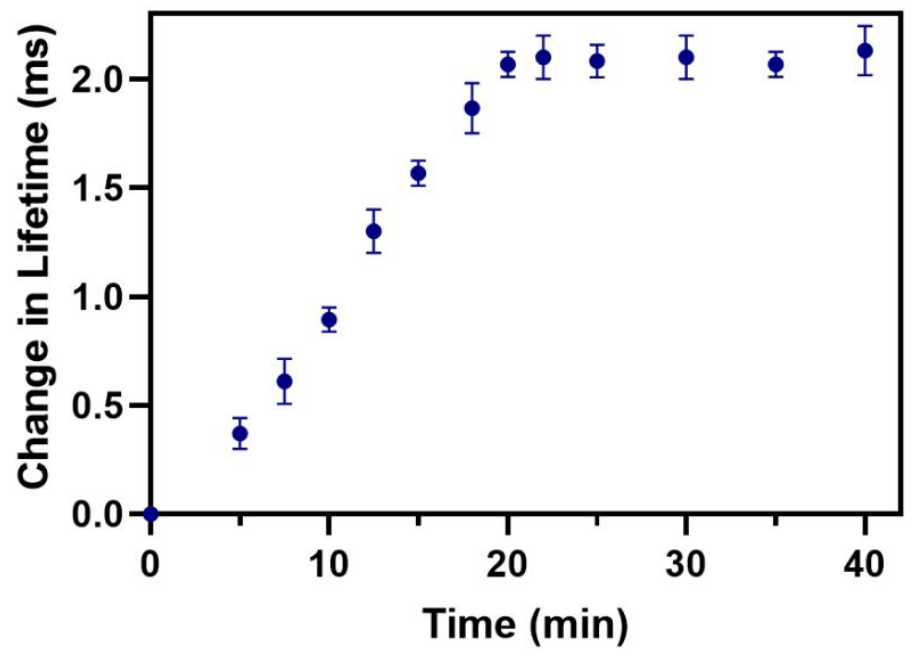

Fig. S15. Changes in luminescence lifetime values of 1-Tb $(0.1 \mathrm{mM})$ as a function of time in the presence of PEP $(500 \mathrm{nM})$ in HEY cells overexpressing PKM2 $\left(\lambda_{\mathrm{ex}}=337 \mathrm{~nm}\right)$. Error bars represent standard deviation $(n=3)$.

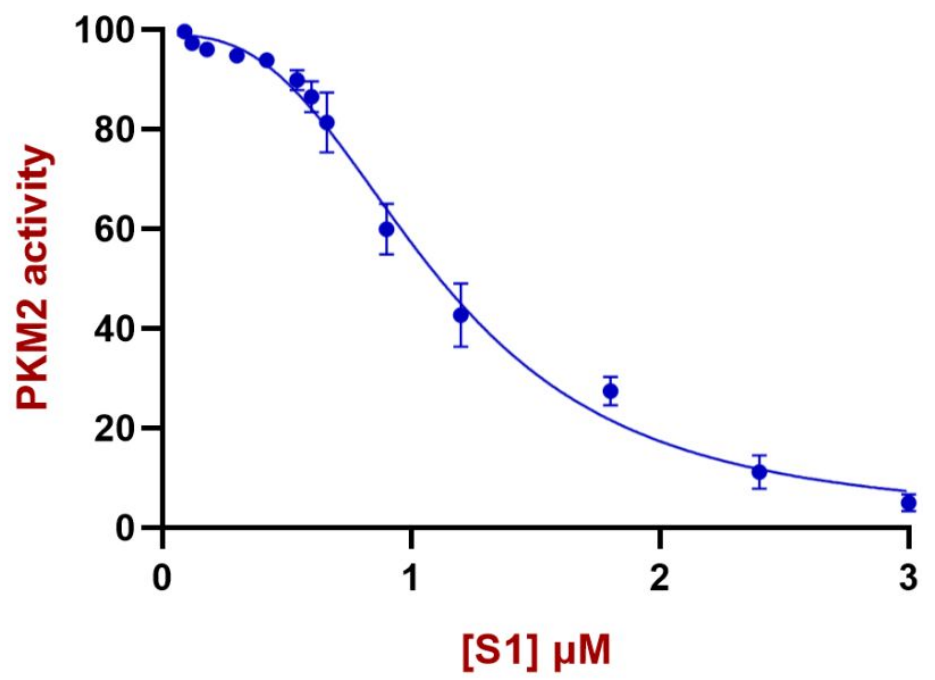

Fig. S16. Dose-response curve of compound S1 in LDH-coupled assay for PKM2 activity. Error bars represent standard deviation $(n=3)$. 


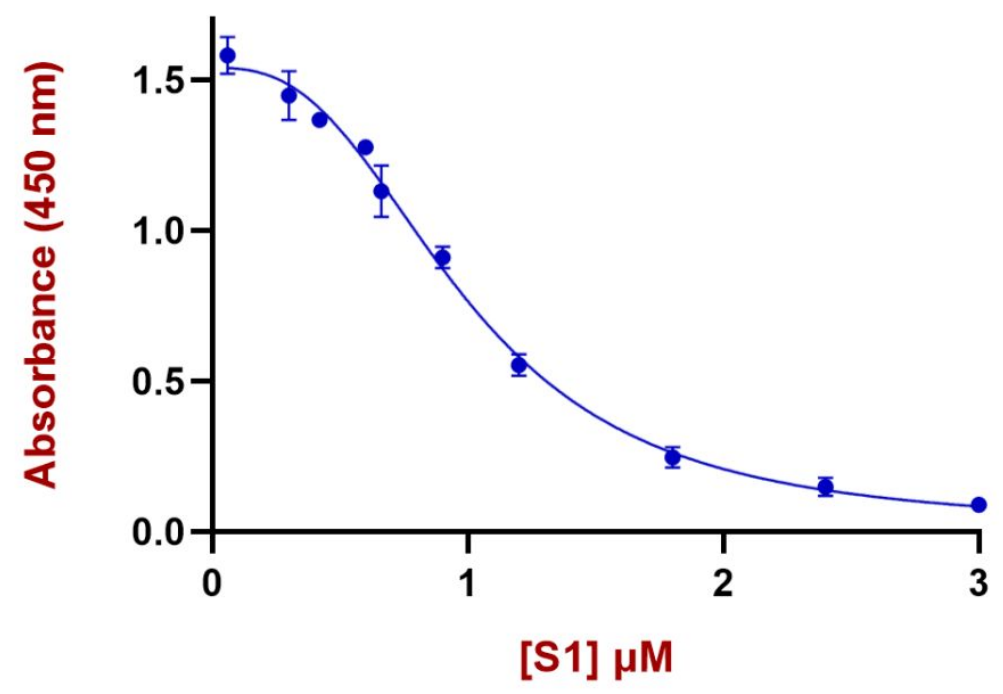

Fig. S17. Dose-response curve of compound S1 in PKM2 ELISA assay. Error bars represent standard deviation $(n=3)$.
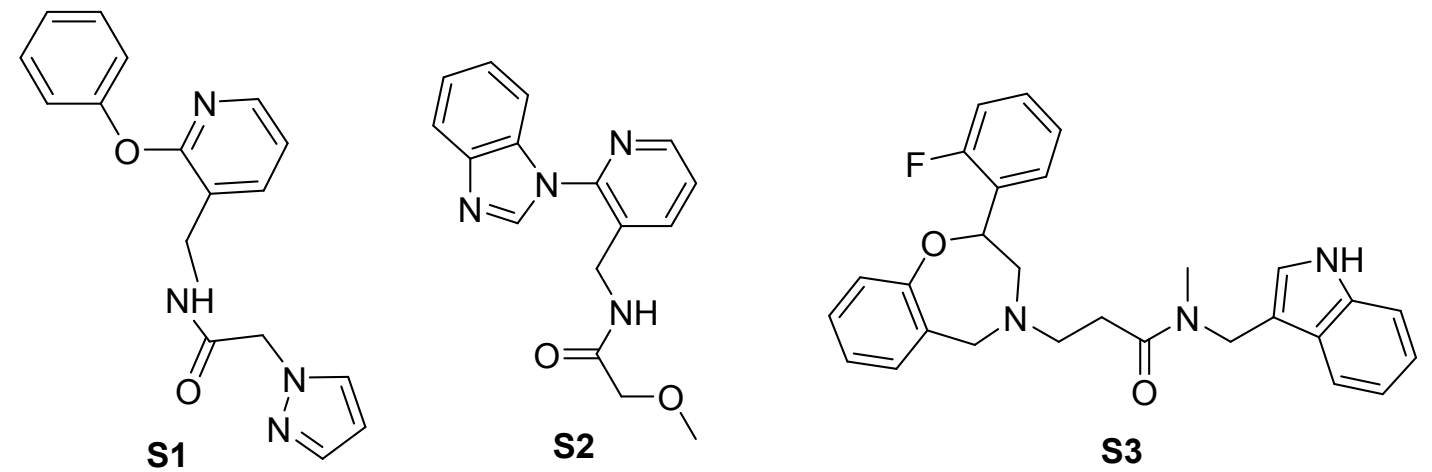

Fig. S18. Chemical structures of compounds SI and SII. 


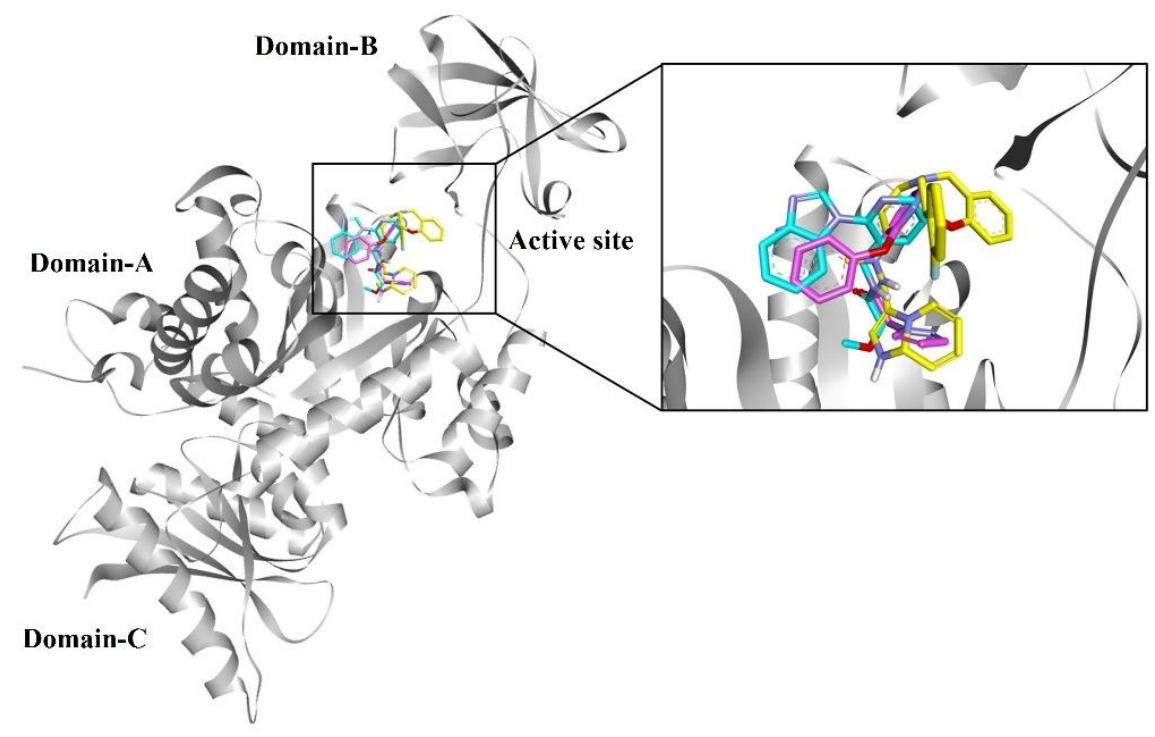

Fig. S19. Superimposition of docked poses of compounds S1 (pink), S2 (blue), and S3 (yellow).
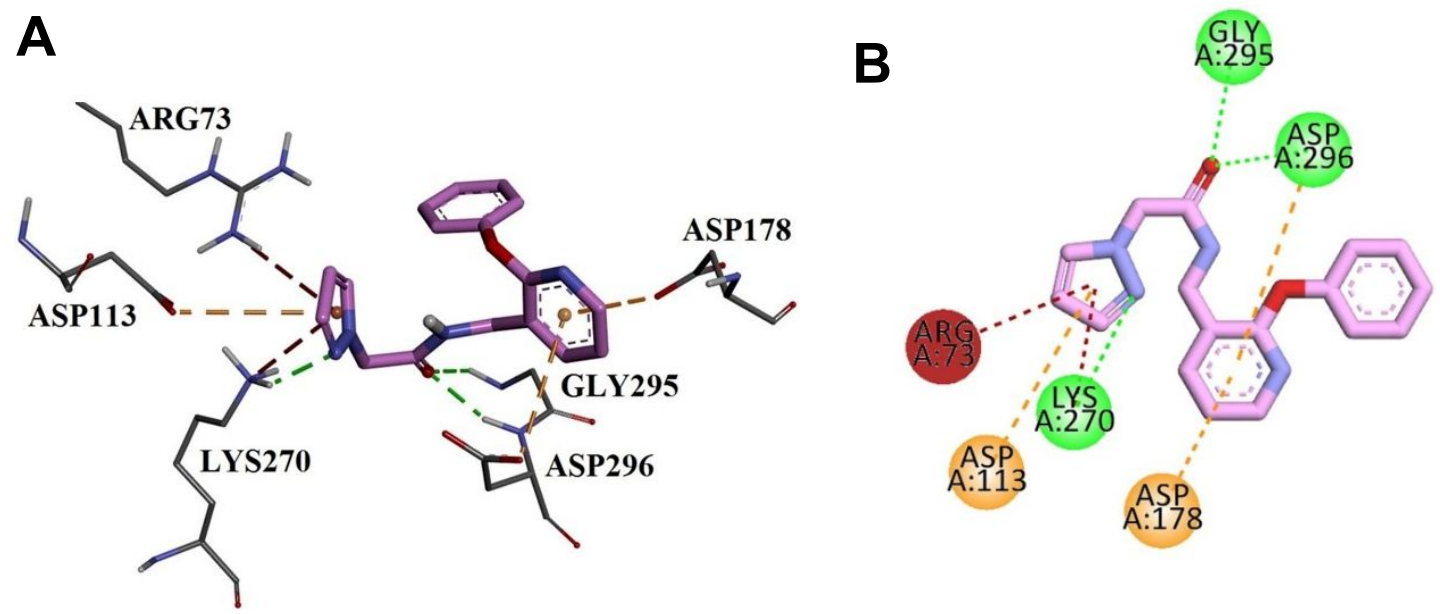

Fig. S20. (A) 2D and (B) 3D docked binding mode and interactions of compound S1 inside active site of hPKM2. Colors of dotted lines explain different interactions: hydrogen bond (green), Pi-cation (brown) and Pi-anion (golden). 
(A)

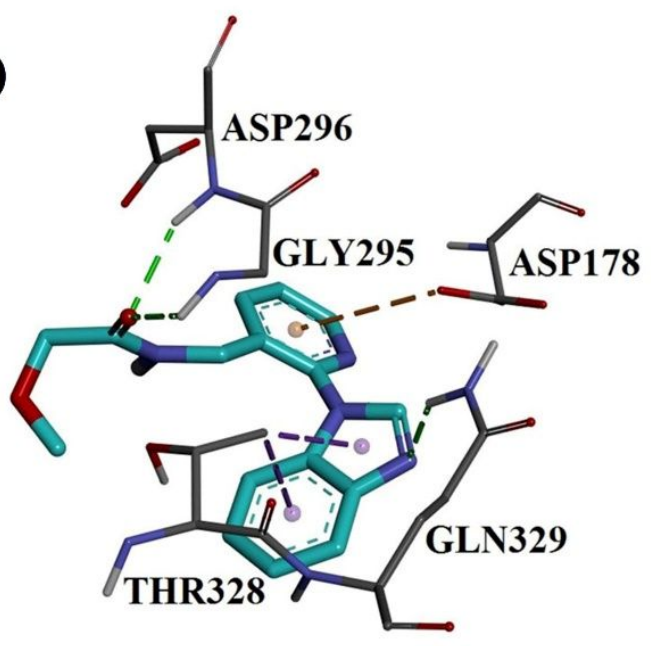

(B)

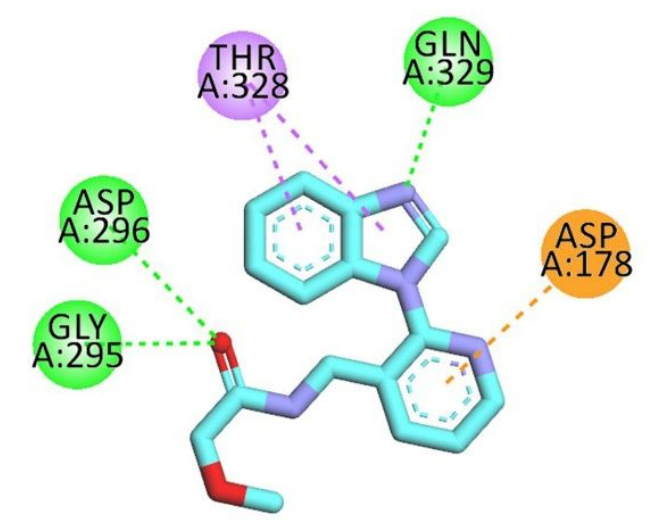

Figure S21. Docked binding mode and interactions of compound S2 inside active site of hPKM2. (A) 3D illustration. (B) 2D interaction diagram. Colors of dotted lines explain different interactions: hydrogen bond (green), Pi-sigma (purple) and Pi-anion (golden).
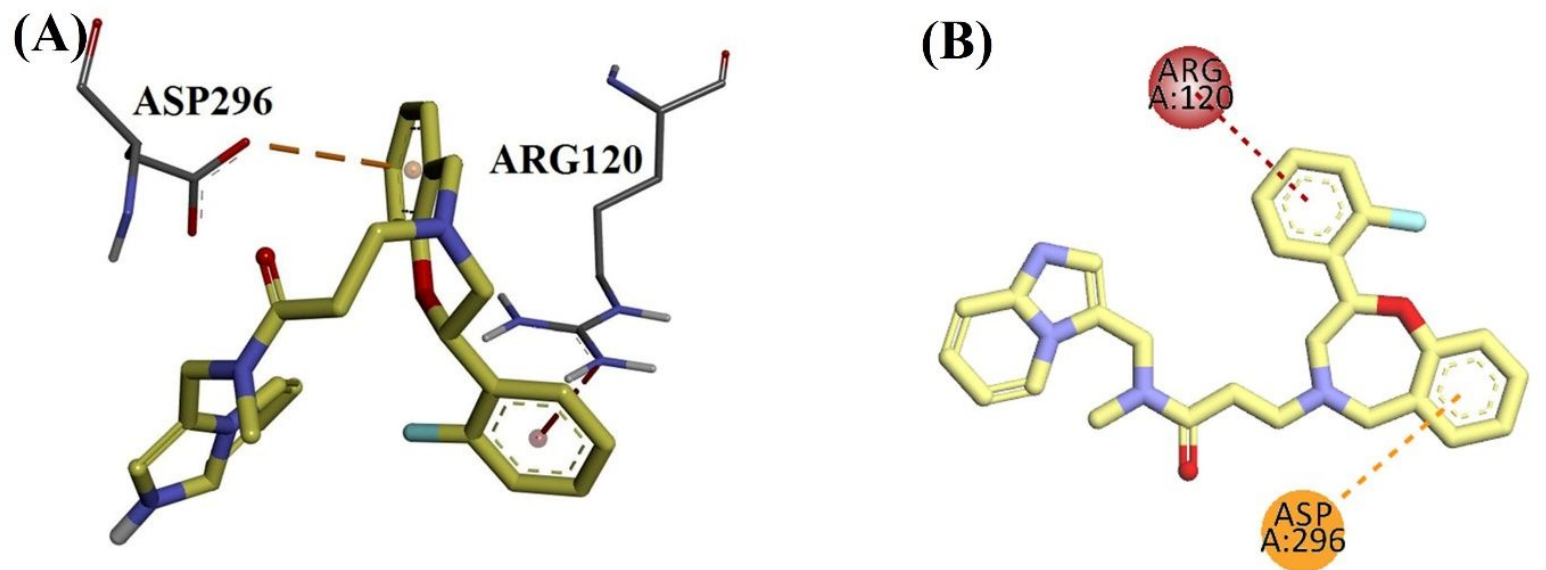

Figure S22. Docked binding mode and interactions of compound S3 inside active site of hPKM2. (A) 3D illustration. (B) 2D interaction diagram. Colors of dotted lines explain different interactions: Pi-cation (brown) and Pi-anion (golden). 


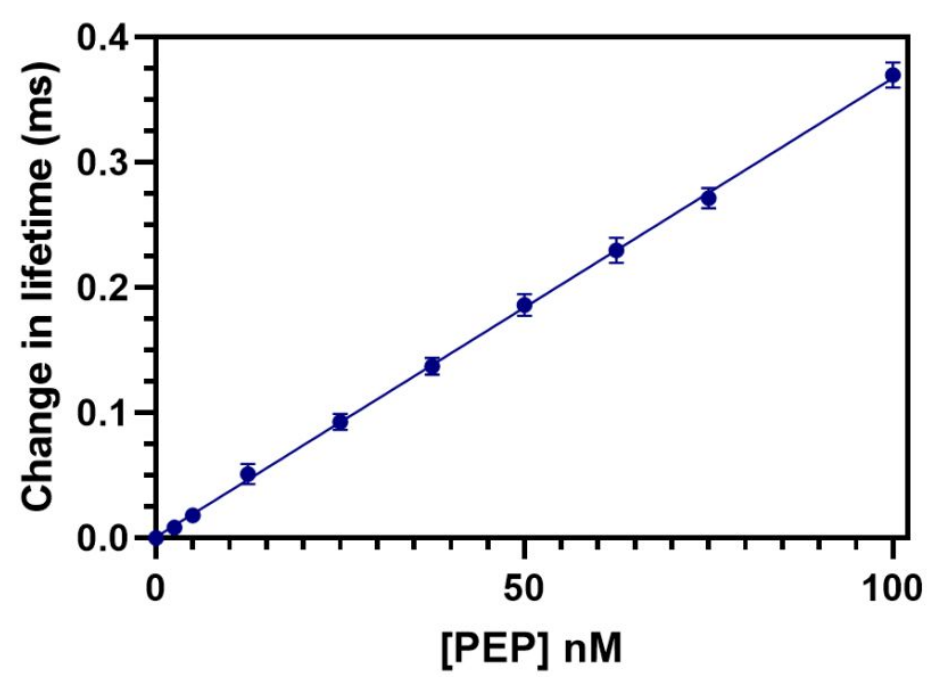

Fig. S23. Changes in luminescence lifetime values of 1-Tb $(0.1 \mathrm{mM})$ as a function of added PEP concentration (0-100 nM) to HEY cells overexpressing PKM1 $\left(\lambda_{\text {ex }}=337 \mathrm{~nm}\right)$. Error bars represent standard deviation $(n=3)$.

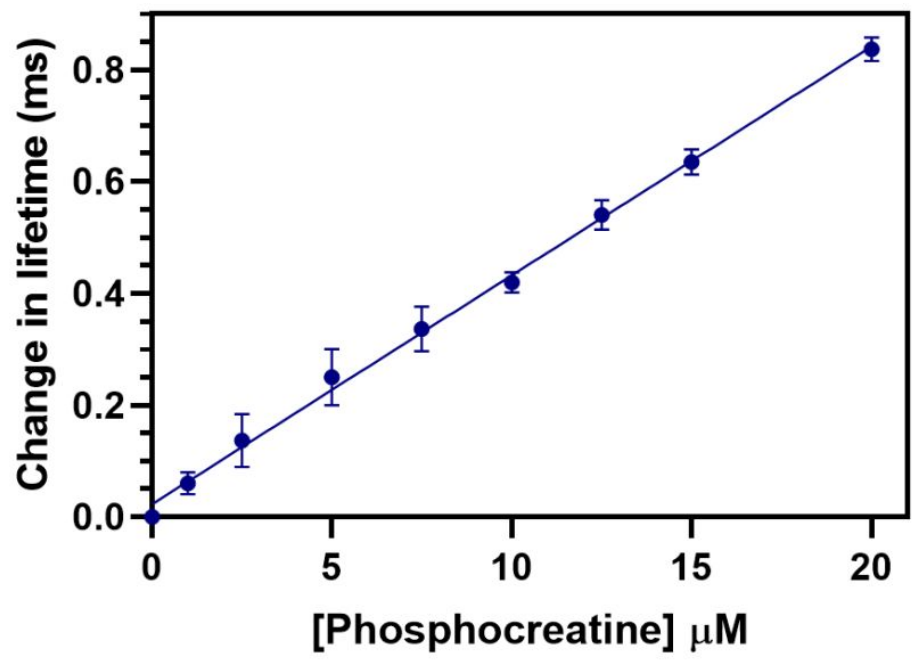

Fig. S24. Changes in luminescence lifetime values of 1-Tb $(0.1 \mathrm{mM})$ as a function of added phosphocreatine concentration $(0-20 \mu \mathrm{M})$ to human skeletal muscle fibroblasts expressing muscle creatine kinase $\left(\lambda_{\mathrm{ex}}=337 \mathrm{~nm}\right)$. Error bars represent standard deviation $(n=3)$. 


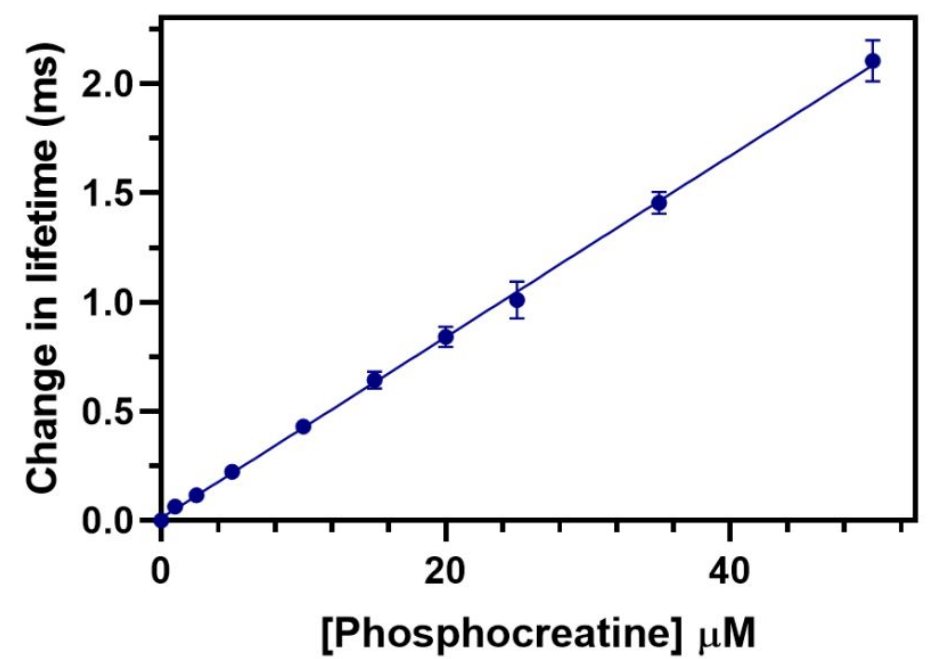

Fig. S25. Changes in luminescence lifetime values of 1-Tb $(0.1 \mathrm{mM})$ as a function of added phosphocreatine concentration $(0-50 \mu \mathrm{M})$ to murine cardiomyocytes expressing mitochondrial creatine kinase (Sterptolysin O permeabilized) $\left(\lambda_{\text {ex }}=337 \mathrm{~nm}\right)$. Error bars represent standard deviation $(n=3)$.

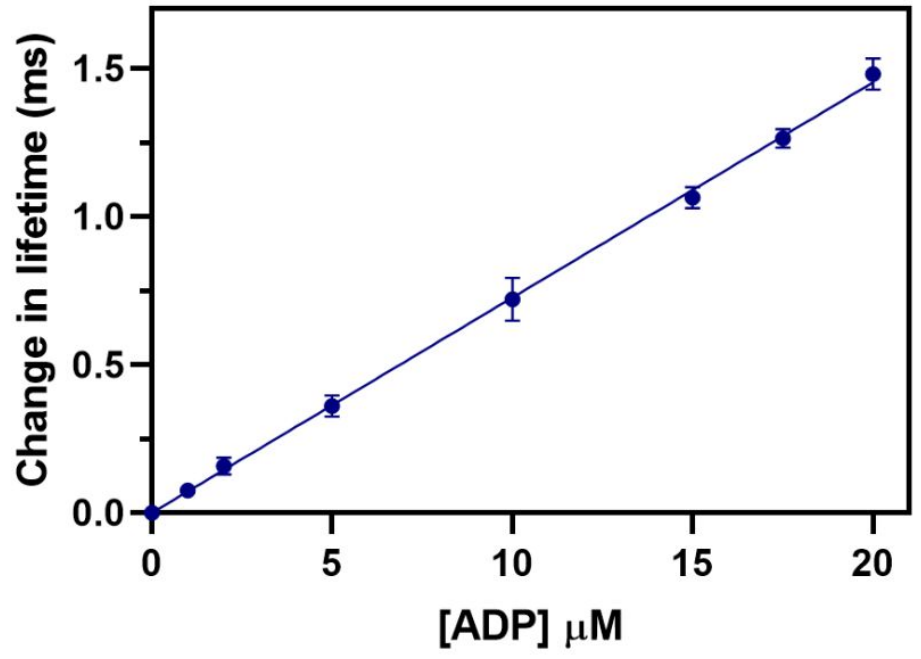

Fig. S26. Changes in luminescence lifetime values of 1-Tb $(0.1 \mathrm{mM})$ as a function of added ADP concentration $(0-20 \mu \mathrm{M})$ to PC-3M (Sterptolysin O permeabilized) expressing ATP synthase in the presence of phosphate $(1 \mathrm{mM})\left(\lambda_{\mathrm{ex}}=337 \mathrm{~nm}\right)$. Error bars represent standard deviation $(\mathrm{n}=3)$. 
Table S1. Effect of viscosity on $V_{\max }$ of PKM2 in HEY cells.

\begin{tabular}{|c|c|}
\hline Viscosity (cP) & $\begin{array}{c}\text { Vmax }(\mathrm{mm} / \mathrm{min} / \mathrm{mg} \\
\text { protein) }\end{array}$ \\
\hline 1.0 & $0.0041 \pm 0.0002$ \\
\hline 2.5 & $0.0041 \pm 0.0002$ \\
\hline 5.0 & $0.0040 \pm 0.0001$ \\
\hline 7.5 & $0.0035 \pm 0.0001$ \\
\hline 10 & $0.0029 \pm 0.0001$ \\
\hline 15 & $0.0023 \pm 0.0001$ \\
\hline
\end{tabular}

Table S2. Optimized viscosities for screening ATP-generating enzymes.

\begin{tabular}{|c|c|}
\hline Enzyme & Viscosity (cP) \\
\hline Pyruvate kinase M1 & 5.5 \\
\hline Muscle creatine kinase & 4.6 \\
\hline Mitochondrial creatine kinase & 3.9 \\
\hline ATP synthase & 3.2 \\
\hline
\end{tabular}

\section{References:}

1 S. H. Jung, K. Y. Kim, J. H. Lee, C. J. Moon, N. S. Han, S.-J. Park, D. Kang, J. K. Song, S. S. Lee, M. Y. Choi, J. Jaworski, J. H. Jung, Self-assembled $\mathrm{Tb}^{3+}$ complex probe for quantitative analysis of ATP during Its Enzymatic Hydrolysis via time-resolved luminescence in vitro and in vivo. ACS Appl. Mater. Interfaces, 2017, 9, 722-729.

2 B. Zheng, F. Liu, L. Zeng, L. Geng, X. Ouyang, K. Wang, Q. Huang, Overexpression of pyruvate kinase type M2 (PKM2) promotes ovarian cancer cell growth and survival via regulation of cell cycle progression related with upregulated CCND1 and downregulated CDKN1A expression. Med. Sci. Monit. 2018; 24, 3103-3112.

3 W. Li, J. Liu, Y. Zhao, PKM2 inhibitor shikonin suppresses TPA-induced mitochondrial malfunction and proliferation of skin epidermal JB6 cells. Mol Carcinog. 2014, 53, 403-412.

4 G. Chiappetta, G. Tallini, M. C. De Biasio, et al., FRA-1 expression in hyperplastic and neoplastic thyroid diseases. Clin. Cancer Res. 2000, 6, 4300-4306.

5 J.-H. Zhang, T. D. Y. Chung, and K. R. Oldenburg, A simple statistical parameter for use in evaluation and validation of high throughput screening assays. J. Biomol. Screen. 1999, 4, 67-73. 